\title{
Study on a novel power emergency plan based on the virtual reality technology
}

\author{
Xiangning HE, He PAN, Xianqi LI, Guiyun HUANG, Dehe WANG, Xin HUANG \\ Automation of Electric Power Systems, Training and Evaluation Center of Guizhou Power Grid \\ Corporation, Guiyang, 550000, China
}

email: 2011302540006@whu.edu.cn

\section{Keywords: Power accident; Emergency drill; Virtual reality technology}

\begin{abstract}
This paper investigated power emergency drills situation in domestic and foreign, compared practical and virtual drills from the aspects of the scale and investment of the drill and the effect of drill. Then proposed the concept of power emergency response drills on the basis of virtual reality technology, and designed a novel power emergency plan based on virtual reality technology.
\end{abstract}

\section{Introduction}

Corresponding to the economic development, the development of the demand for energy is increasing rapidly, the construction of power grid is more stringent due to the increasing of electricity consumption, which requires power grid is stronger and higher levels of self-healing ability to provide stable and quality power supply. The natural disasters and the power misoperation under the jurisdiction of enterprises will cause the power system accident [1,2], even the large area blackout of power grid.

All accidents of American are the same category and the power accident is also covered. The United States power industry mainly uses three kinds of exercises, which are desktop exercises, functional exercises, practical exercises, some special emergency drills will also be carried out to different types of power facilities. Nuclear power is France's mainly supplied energy, so the nuclear power industry emergency management occupy an important position in the emergency exercise of the French power industry [3]. The emergency drills are completed by the government authorities and nuclear power units usually. For the Canadian power industry, the evaluation of emergency drills will be conducted to evaluate all kinds of the electrical operation of the exercise, all emergency drills participants must make a summary of their operations.

The construction of emergency plan system of Chinese power enterprises covers four aspects: natural disasters, accidents, public health incidents and social security incidents. May 2005, the office of the State Council issued the national power grid large area power outage emergency plan, marking the establishment of the state power safety emergency mechanism. Since then, the China State Grid Corp and the Power Grid Corp have conducted large-scale comprehensive emergency drills. October 12, 2006, the provincial power grid large area power outage emergency joint exercise in Guangdong province took the lead and lay a good foundation for the rest of the country in the abstract of the large-scale comprehensive emergency drills [4]. China State Grid Corp launched a large area blackout event emergency joint drill in Zhejiang Province in 2007. Which involves government, power grid enterprises, power generation companies and users. But this kind of exercise only focuses on the exercise linkage and coordination but lacks of authenticity.

Therefore, to carry out the power emergency drill simulation research approach with combined virtual and real technology, establish and improve the scientific prevention mechanism, improve the power grid recovering speed in power accident, to ensure stable operation of power grid and power supply reliability is a urgent task and challenge. 


\section{Study for power emergency practical drill}

\subsection{Scale and investment of practical drill}

Practical drill should be a comprehensive exercise in accordance with the strict classification of the exercise, and has a large scale and personnel involved in the exercise are not just limited to the power companies. For example, the largest scale emergency drill in history at Shanghai power grid has more than 800 people involved. Summed up the participating units in drills as follows: city government, which is organizer; power enterprises, the main implementation units including power supply companies, power stations and other units; municipal economic commission, coordinating each unit to participate in the exercise; municipal government emergency office, leading all participating units ready for exercise; safety supervision bureau, safety supervision departments, organizing experts of joint exercises for guidance, analysis and evaluation; the municipal government information office, the news media, joint planning and implementation scheme for joint propaganda exercises, held a press conference; the important and high-risk users[5], including police, hospitals, banks, airports as the participating units to setup and complete the exercise program. The investment of manpower, physical resource and financial resource for large-scale joint exercises is quite amazing, so this drill pattern will be carried out after repeated audits, and long-term planning and preparation. The resource input of the virtual drills is incomparable to practical drills.

\subsection{The effect of practical drills.}

Practical drills focus on procedural norms, highlighting the linkage, and actual combat, is the most practical inspection and exercise of the emergency exercise capacity of large area blackout. First of all, the practical drill can improve the linkage of the various sectors of the community. In view of the characteristics of large scale, massive participating units, complex technical supports of practical drills, this kind of drills can be used to increase coordination among the various units. This exercise will become an important reference for the emergency response, the linkage of social units will have an example to follow. Secondly, practical drills of power system will use the standby power equipment and the creation of the exercise environment will not consider the cost, as close as possible to simulate the real accidents. Emergency units in the disposal of real accidents will not feel strange and panic for the accident environment, the speed to adapt will be greatly accelerated, the accident disposal speed will be correspondingly accelerated and such an accident drill will also be an important opportunity to test the emergency plan. Finally, enhancing the participation of all sectors of society, large joint exercises require the participation of the community and employees from all walks of life can be used as part of the exercise. After the occurrence of unexpected events, it can avoid a wide range of panic and chaos.

\section{Study for power emergency virtual drill}

Virtual drill is a common practical pattern, whose plan and implementation are more simple compared to practical drill. Virtual drills are mainly based on various power professional systems or software, but not all the systems and hardware facilities are used in general virtual drill. Virtual exercises should be functional exercises in accordance with the strict classification of exercises. Drills do not need joint relevant units of society except for the power sectors due to the small scope involved, and so the content of drill is more professional and targeted[6]. Power emergency virtual drill system includes: video communication system, simulation system of dispatcher training, simulation system of substation operation, secondary power grid simulation system, simulation of SCADA, simulation software of remote terminal unit (RTU) and the simulation system of integrated automation substation and the centralized control center of substation. The architecture of these simulation systems is shown in figure 1: 


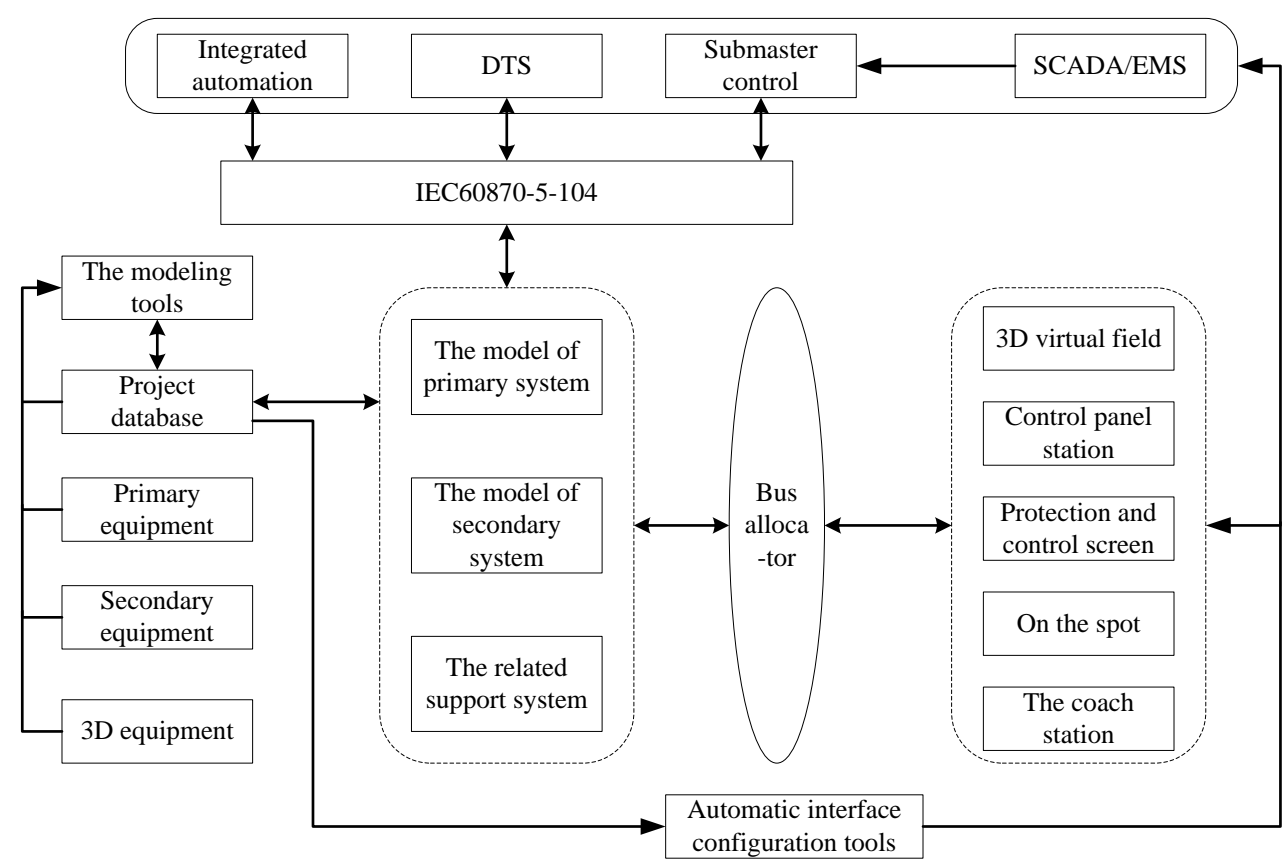

Figure. 1 Software Structure of virtual exercise

\subsection{Scale and investment of virtual drill}

The scale of the virtual drill is much smaller compared with practical exercises and normally limited to power companies, such as production technology department, scheduling center, marketing department, substation operation, maintenance department and other departments. The scale of virtual drill is not enough to cause a strong and widespread social concern. Virtual drill has less materials and manpower but the input in hardware and software can not be underestimated. First, the practice has a very high demand for the indoor environment, the layout of the site should be convenient to observe and evaluate[7], but also to facilitate the operation of the exercise. Speaker, lighting and other equipment will be used to enhance the effect of virtual experience. Secondly, the construction of computer network is one of the important preparatory work of the pre-exercise. Drill will be carry out among multiple departments, so the cooperation is needed. Because the data need to be shared, the routing of computer network will be very complicated. Finally, the introduction and use of various simulation software is also a difficult problem. Local characteristics should be taken into account by various power companies in the virtual exercise. These systems, software should make changes and adjustments according to the parameters of the power grid and the corresponding data of the substation.

\subsection{Effect analysis of virtual drill}

Time limit for Virtual exercise is relatively loose, and it can be tolerated if practice schedule can not keep up with the plan. The contents of large scale joint exercises are formulated by repeated auditing. Fault settings and other links are carefully arranged, so it can not be easily changed and the whole process is determined. Comparatively, virtual drill is more flexible and diverse. In addition, the virtual drill process can be completed in a number of important parts, and focus on the important links[8]. Because of the distribution of the exercise time is more loose, more extensive training content can be added as a extension.

The pertinence and the specialty of virtual drill is very strong. Only professional person can operate the related software and system, and the operation process should be very normative. In addition, the content of the exercise is more abundant, the setting of the fault and the methods of the corresponding disposal are changeable, so it is suitable for the training of professional personnel of the strain capacity and professional disposal capacity. Because the virtual practice has no limit about time and the content of the exercise, the process management will be more flexible. If we found error in a link we can jump to other links, so the error-tolerant rate of the drill is greatly improved. It is easy to evaluate the exercise personnel by virtual drill, and in addition to power 
trainees, there are other industries staff, it can be used for all exercise personnel.

\section{Power emergency response drill based on virtual reality technology}

Power accident has a relatively big difference with virtual practice, the main reason is that the two exercises have different emphasis, and they focus on different emergency index of text. The scale of investment and resource in practical exercises are far more than virtual exercises, virtual exercises can not match with practical exercises at authenticity form the effect of exercises. But also because the investment of practical drills is too large, it can not be often organized. In addition, the linkage is a major feature of practical exercises, the various sectors of the society will be involved. Although virtual drills does not have these advantages, but it has irreplaceable functions in the field of power professional skills, equipment operation and so on. The ideal emergency drill pattern should be able to play the advantages of the two patterns and avoid the disadvantages. The research on power emergency response drill based on virtual reality technology will help to improve the emergency response efficiency [9]. Determining a scientific and reasonable emergency drill pattern will help emergency personnel to find the emergency state more quickly and to be more adapted to emergency environment. A better effect power emergency plan based on the virtual reality technology is the key of this paper. As shown in figure 2, an power emergency plan based on the virtual reality technology has been proposed in this paper.

This is a kind of society - power network, practical and virtual drill patterns. First, the society and the power grid are interrelated. The first layer is the infrastructure, the sudden incidents or accidents have a certain impact on the infrastructure. For the infrastructure, different movements will be taken by the society and the power grid, and different emergency activities will be taken. On the one hand we will expand the social emergency rescue, road traffic of the accident scene will be blockaded [10]. On the other hand equipment will be repaired by the power grid corporation, investigation and analysis of the accident also be carried out. The second layer is the power operation, which illustrates the development of the accident has endangered the normal function of power grid. Important power unit may be power cut while it's important to ensure these units will not be power cut. Optional methods will be changed to supply power in important areas as fast as possible by dispatch. The third layer is the power recovery. In this layer, equipment, lines after successful repair can be put into operation at any time. But it is for not too serious accidents. If it is necessary for large area blackout, all black accident to carry out black start, which needs society and the power grid contact closely, we need to contact with the black start power supply conditions, including large factory owned motor, captive power plants etc to complete the assigned power tasks. Finally, it's the evaluation of the work, including the accident evaluation, the performance evaluation of the units, the evaluation of the participation etc. The whole model has a certain order, social and power grid emergency response should be coordinated with each other. In emergency activities, by using the method of combining the virtual and real technology, the high cost of emergency simulation activities are implemented in the simulation system. The system organically combines the actual combat with the virtual drill, and the emergency response is relatively high, which can lead the emergency personnel to enter the emergency state quickly. 


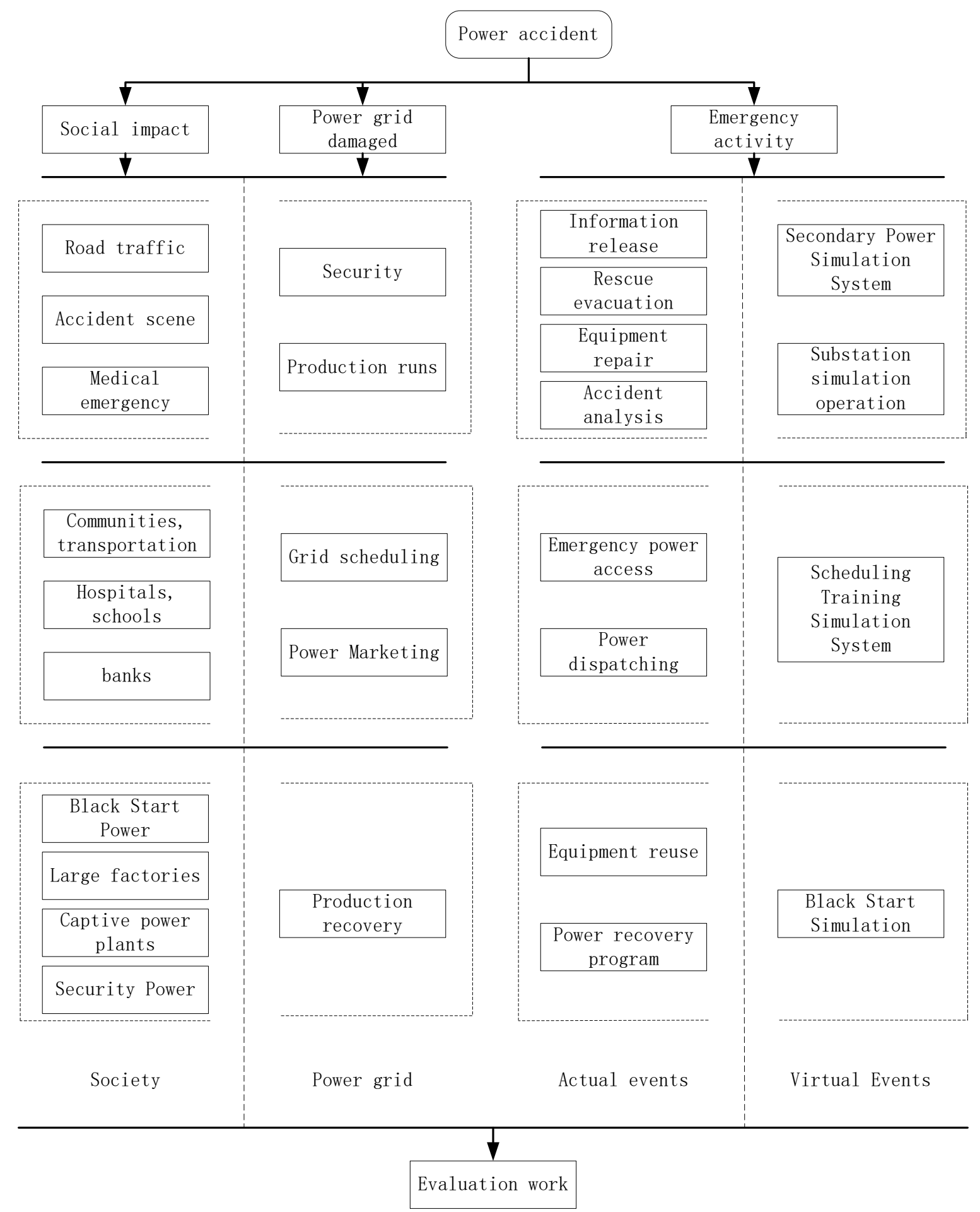

Figure.2 Simulation plan for emergency disposal

\section{Conclusion}

This paper analyzed the background of power emergency response drills based on the virtual reality technology, and the scale investment and effect of the practical and virtual drills were summarized respectively. Two kinds of exercises have different emphasis, and the emergency index of examination is not the same, the most ideal emergency drill is to play the advantages of the two patterns. Through the comparison and summary of the practical and virtual drills, a novel simulation scheme of power emergency drill pattern based on virtual reality technology is proposed, which can be used to provide a reference for the development of emergency drills. 


\section{References}

[1] Yixing Qi. Study on the Crisis Management of Large Area Blackout [D]. Shan Dong University,2012.

[2] Xinyan $\mathrm{Wu}$ and so on. Advance in research on urban emergency management capability assessment at home and abroad[J]. Journal of Natural Disasters, 2007,06:109-114.

[3] Shixiang Wang. Key Factors and Regulatory Measures for Widespread Blackouts [J]. China Electric Power,2014,01:77-81.

[4] Rui Yang. Power grid emergency management system and emergency capability evaluation [D]. North China Electric Power University, 2011.

[5] Sige Li and so on. A Prospective Research on Technical Assessment Indices of Emergency Management Capability in Urban Power Network[J]. Power System Technology, 2007, 22:17-20.

[6] Jianhua Zhang and so on. Recommends of the regional power grid emergency management mechanism of China[J]. Automation of Electric Power Systems, 2009, 04:40-44+52.

[7] Chaoyang Zhu and so on. Research on Theory and Technical System for Power Emergency Management[J]. Power System Technology,2011,02:178-182.

[8] Fangfang Jang and so on. Application of Virtual Reality in Substation Simulation and Training System[J]. High Voltage Engineering,2005,07:68-70.

[9] Hui Qiao and so on. Design and implementation of training for the power of three-dimensional interactive simulation platform[J]. Electric Power Automation Equipment, 2013, 06:157-162.

[10] Yang Xiao. Situation pattern based research on simulation platform for power emergency exercise [D]. Shanghai Jiao Tong University, 2013. 